\title{
COMPARISON OF HYDRAULIC CONDUCTIVITY VALUES OBTAINED FROM EMPIRICAL FORMULAE AND LABORATORY EXPERIMENTS
}

\author{
Mario Halaํ, Lubomír Petrula ${ }^{1}$, Zakaraya Alhasan² \\ ${ }^{1}$ Institute of Water Structures, Faculty of Civil Engineering, Brno University of Technology, Antonínská 548/1, \\ 60190 Brno, Czech Republic \\ ${ }^{2}$ Institute of Geotechnics, Faculty of Civil Engineering, Brno University of Technology, Antonínská 548/1, 60190 \\ Brno, Czech Republic
}

Link to this article: https://doi.org/10.11118/actaun202068040669

Received: 20. 10. 2018, Accepted: 17. 8. 2020

To cite this article: HALA MARIO, PETRULA LUBOMÍR, ALHASAN ZAKARAYA. 2020. Comparison of Hydraulic Conductivity Values Obtained from Empirical Formulae and Laboratory Experiments. Acta Universitatis Agriculturae et Silviculturae Mendelianae Brunensis, 68(4): 669-678.

\begin{abstract}
Hydraulic conductivity determination plays an essential role in the investigation of groundwater flow regime which can then influence many field problems such as pumping capabilities in the area, transport of contaminant or heat and soil internal erosion. Numerous equations based on dimensional analysis or experimental measurements have been published since the end of the $19^{\text {th }}$ century for the determination of hydraulic conductivity. However, not all of these formulae are applicable for every material and all of them bring some uncertainty in the value of hydraulic conductivity. This paper contains a description of experimental research carried out concerning the determination of hydraulic conductivity for four types of sand with different grain size distribution curves and variable porosity. Obtained values of hydraulic conductivity ranged from $1 \times 10^{-4}$ to $4 \times 10^{-3}$ according to the sample porosity. The series of experiments consisted of 160 separate tests conducted in order to obtain relevant statistical sets. In this paper, the experimental data are discussed and compared with hydraulic conductivities obtained from 6 empirical formulae recommended in a previous study. The comparison showed that some empirical formulae provide a good agreement with the experimental data (the most precise were formulae published by Terzaghi and by Sauerbrey). However, some formulae showed high deviation from measured data (formula published by Zamarin).
\end{abstract}

Keywords: empirical formulae, hydraulic conductivity, porosity

\section{INTRODUCTION}

Empirical equations have been used to determine hydraulic conductivity for the purposes of many practical studies because of the very costly and time-consuming nature of field pumping tests. The empirical formulae have wide application in both practical and experimental studies (Julínek et al., 2020; Ghafoori et al., 2020; Petrula et al., 2018). However, such empirical equations have been derived for specific conditions and there are limits to their applicability. It was observed many times that completely different values of hydraulic conductivity were determined using various empirical formulae and then averaged even if some formulae should not be applied for given soil. Results from such procedures show big overestimation or underestimation of real hydraulic conductivity. Therefore, empirical formulae should serve only as a support tool for hydraulic conductivity determination. Therefore, a study presented in this paper was made where chosen empirical formulae are analysed and the over/ underestimation effect is determined. The comparison of laboratory data with empirically derived formulae was done to show differences between formulae 
and to show how much the calculated values differ from the "true" measured values. This study then shows possible inaccuracies when using empirical equations in research or practical cases.

Dimensional analysis based on the DarcyWeisbach equation of head loss (Vuković and Soro, 1992) may be considered the most common method of analysis used to derive empirical equations for the determination of hydraulic conductivity. A detailed analysis was presented by Ř́ha et al. (2018), who proposed an empirical formula for the determination of hydraulic conductivity based on characteristic pore diameter and the porosity function. Several studies have employed the principle of deriving the characteristic pore diameter from the effective grain size $d_{e}$ (Krüger, 1918; Zamarin, 1928; Zunker, 1932; Sauerbrey, 1932; Kozeny, 1953; VNIIG, 1991). The first simple linear dependence between hydraulic conductivity and soil porosity was probably proposed by Hazen (1892). Within most of the formulae that determine hydraulic conductivity based on soil porosity (Hazen, 1892; Slichter 1899; Krüger, 1918; Terzaghi, 1925; and Kozeny, 1927) the influence of soil nonuniformity is not taken into account.

The assessment of previously proposed empirical formulae for the determination of hydraulic conductivity has been carried out by many authors using their own experimental results. For instance, some empirical formulae were analysed by Kasenow (2002). The objective of the recently published laboratory research carried out by Říha et al. (2018) was to summarize the most commonly used empirical formulae and evaluate their applicability and reliability for glass beads by comparing the measured conductivity values with calculated values obtained from the empirical formulae. The rate of agreement was quantified using the sums of standardised squared deviations $\sum_{\varepsilon}$ for the used empirical equations. The formulae were summarized in ascending order based on the $\sum \varepsilon$ value. For the current paper, six empirical formulae for the determination of hydraulic conductivity with minimum $\sum \varepsilon$ values (as presented by Říha et al. (2018)) were selected. These are formulae which were proposed by KozenyCarman (Carrier (2003), Zunker (1932), Terzaghi (1925), Zamarin (1928), Pavchich (VNIIG, 1991) and Sauerbrey (1932)) (see Tab. 6 within the (2018) paper by Ř́ha et al.). The hydraulic conductivity obtained from these empirical formulae are compared with experimental data from laboratory research carried out for four types of sand. A discussion on the final results and a brief conclusion are presented.

\section{Empirical Formulae}

For the purposes of this paper, six hydraulic conductivity formulae were selected. The following text summarizes the chosen formulae. The conditions for the use of each formula are described in terms of grain size and effective grain size.

\section{Terzaghi (1925)}

$k=\frac{g}{v} C_{T}\left(\frac{n-0.13}{\sqrt[3]{1-n}}\right)^{2} d_{10}^{2}$

where $g$ is the gravitational acceleration, $v$ is the kinematic viscosity, $n$ is the volumetric porosity, $d_{10}$ is the grain diameter for $10 \%$ finer by weight and $C_{T}$ is the empirical coefficient, which depends on the grain shape $\left(C_{T}=10.7 \times 10^{-3}\right.$ for smooth grains and $C_{T}=6.1 \times 10^{-3}$ for coarse grains). This equation can be used for largegrained sands.

\section{Zamarin (1928)}

$k=\frac{g}{v} C_{Z A} C_{n} \frac{n^{3}}{(1-n)^{2}} d_{e}^{2}$,

where $C_{Z A}=8.64 \times 10^{-3}$ is the empirical coefficient and $C_{n}$ is a factor that depends on the porosity:

$C_{n}=(1.275-1.5 n)^{2}$,

$d_{e}$ is the effective grain size, and for materials containing grains finer than $0.0025 \mathrm{~mm}$ it is given as follows:

$\frac{1}{d_{e}}=\frac{3 \Delta g_{1}}{2 d_{1}}+\sum_{i=2}^{N} \Delta g_{i} \frac{\ln \frac{d_{i}^{g}}{d_{i}^{d}}}{d_{i}^{g}-d_{i}^{d}}$,

where $d_{1}$ is the largest diameter of the finest fraction, $\Delta g_{1}$ is the weight of the finest fraction, $\Delta g_{i}$ is the fraction of mass that passes between sieves $i$ and $i+1$ where $i$ is the smaller sieve, $d_{i}^{g}$ and $d_{i}^{d}$ are the maximum and minimum grain diameter corresponding to the $i$-th fraction, and $N$ is the number of fractions. For materials that do not contain fractions finer than $0.0025 \mathrm{~mm}$, the effective grain size can be obtained as follows:

$\frac{1}{d_{e}}=\sum_{i=1}^{N} \Delta g_{i} \frac{\ln \frac{d_{i}^{g}}{d_{i}^{d}}}{d_{i}^{g}-d_{i}^{d}}$.

Equation (2) can be used for fine and mediumgrained sands.

\section{Sauerbrey (1932)}

$k=\frac{g}{v} C_{Z} \frac{n^{3}}{(1-n)^{2}} d_{17}^{2}$,

where $C_{z}=3.75 \times 10^{-3}$ is the empirical coefficient and $d_{17}$ is the grain diameter for $17 \%$ finer by weight. This equation can be used for soils with $d_{17}$ up to $5.0 \mathrm{~mm}$.

\section{Zunker (1932)}

$k=\frac{g}{v} C_{z U}\left(\frac{n}{1-n}\right)^{2} d_{e}^{2}$, 
where $C_{Z U}$ is the empirical coefficient, which depends on the porous medium (Tab. I), and the effective grain size $d_{e}$ is given by the formula:

$$
\frac{1}{d_{e}}=\sum_{i=1}^{N} \Delta g_{i} \frac{d_{i}^{g}-d_{i}^{d}}{d_{i}^{g} d_{i}^{d} \ln \frac{d_{i}^{g}}{d_{i}^{d}}}
$$

Equation (7) can be applied for fine and mediumgrained sands.

\section{Pavchich (VNIIG, 1991)}

$$
k=\frac{0.04}{v} \varphi_{1} \sqrt[3]{C_{U}} \frac{n^{3}}{(1-n)^{2}} d_{17}^{2}
$$

where $\varphi_{1}$ is the coefficient, which depends on the grain size ( $\varphi_{1}=1$ for sand, $\varphi_{1}=0.35-0.40$ for gravel) and $C_{U}$ is the coefficient of uniformity. This equation can be used for soils with $d_{17}$ ranging from $0.06 \mathrm{~mm}$ to $1.5 \mathrm{~mm}$.

\section{Kozeny-Carman (Carrier, 2003)}

$k=\frac{g}{u} C_{K C} \frac{6}{d_{e}} d_{e}^{2} \frac{n^{3}}{(1-n)^{2}}$,

where $C_{K C}=480 \pm 30$ is the empirical coefficient and $d_{e}$ equals $d_{10}$. The formula is not appropriate for clayey soils, but it is applicable for silts, sands and gravel sands.

\section{Laboratory Experiments}

For the purposes of this paper, laboratory experiments were carried out in order to evaluate the applicability of the selected empirical formulae for four different types of sand with different grain size distribution curves. 40 hydraulic conductivity measurements were performed for each sand type with variable porosities.

The sands used within this laboratory research were brought from two sand mines (Bzenec and Kora) in the Czech Republic. Bzenec sand ranges from $0.0 \mathrm{~mm}$ to $2.0 \mathrm{~mm}$ while Kora sand ranges from $0.0 \mathrm{~mm}$ to $4.0 \mathrm{~mm}$. A portion of the sand from each location was sifted in order to exclude the fractions finer than $0.1 \mathrm{~mm}$ and coarser than $1.0 \mathrm{~mm}$. As a result, the following four different types of sand were obtained: $\mathrm{B}_{0-2}$ and $\mathrm{B}_{0.1-1}$ (Bzenec 0-2 $\mathrm{mm}$ and
Bzenec 0.1-1 mm, respectively); and $\mathrm{K}_{0-4}$ and $\mathrm{K}_{0.1-1}$ (Kora $0-4 \mathrm{~mm}$ and Kora $0.1-1 \mathrm{~mm}$, respectively) (Fig. 1). Preliminary measurements were conducted on the sands in order to determine the grain size distribution curves (Fig. 2) and the grain size characteristics (Tab. II). Since the $\mathrm{B}_{0.1-1}$ and $\mathrm{K}_{0.1-1}$ sands have the same grain size range, they have identical grain size distribution curves and grain size characteristics. However, there was an essential difference between them in terms of grain shape: the Bzenec grains are more spherical than the Kora grains (Fig. 1), and the former showed a greater tendency towards compaction, and thus lower porosity and hydraulic conductivity, than the latter.

The laboratory experiments were conducted using a permeameter (plastic cylinder), within which the sand sample was subjected to upward vertical seepage flow. The lower part of the permeameter was connected to a water supply and the upper part to an outlet pipe. Piezometers were located below and above the sample.

The upstream boundary condition was set by small water tank which could be moved in vertical direction in order to set different hydraulic gradients. The downstream boundary condition was set by the elevation of the outlet pipe (Fig. 3). Water flowing through the outlet was collected and conveyed back to the large storage tank. Water from the storage tank was pumped back into the movable tank. A photograph of the experimental device is shown in Fig. 3.

Samples were prepared by pouring (free fall) sand into the permeameter. Then, the sample was compacted by putting the permeameter with the sand on a vibrator for different time a duration to achieve various porosity of the sample. The porosity of the sample was determined by weighing and measuring its volume in the permeameter.

The permeameter with the sample was put into the hydraulic circuit and subjected to increasing upward seepage flow by gradually raising the movable tank (Fig. 3). Each time the tank was raised, the piezometric head, hydraulic gradient and seepage discharge through the sample were measured. From one set of the measurements a hydraulic conductivities were calculated, and one average hydraulic conductivity was determined. In total, 160 tests were performed (Tab. III).

\begin{tabular}{ll}
\hline \multicolumn{1}{c}{ Characteristics of the porous medium } & $C_{Z U}[-]$ \\
\hline Uniform sand with smooth, rounded grains & $2.4 \times 10^{-3}$ \\
Uniform composition with coarse grains & $1.4 \times 10^{-3}$ \\
Nonuniform composition & $1.2 \times 10^{-3}$ \\
Nonuniform composition, clayey, with grains of irregular shape & $0.7 \times 10^{-3}$ \\
\hline
\end{tabular}




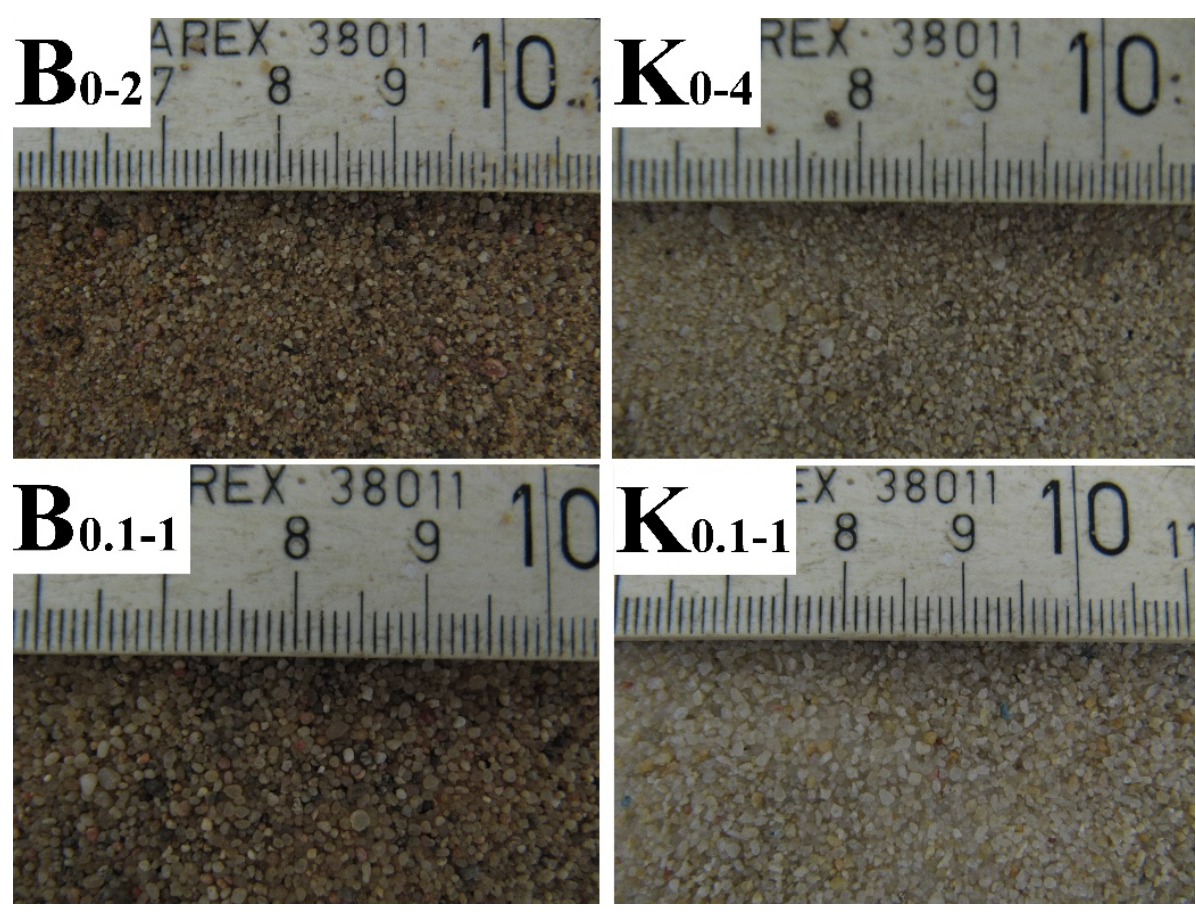

1: Photographs of the 4 sands

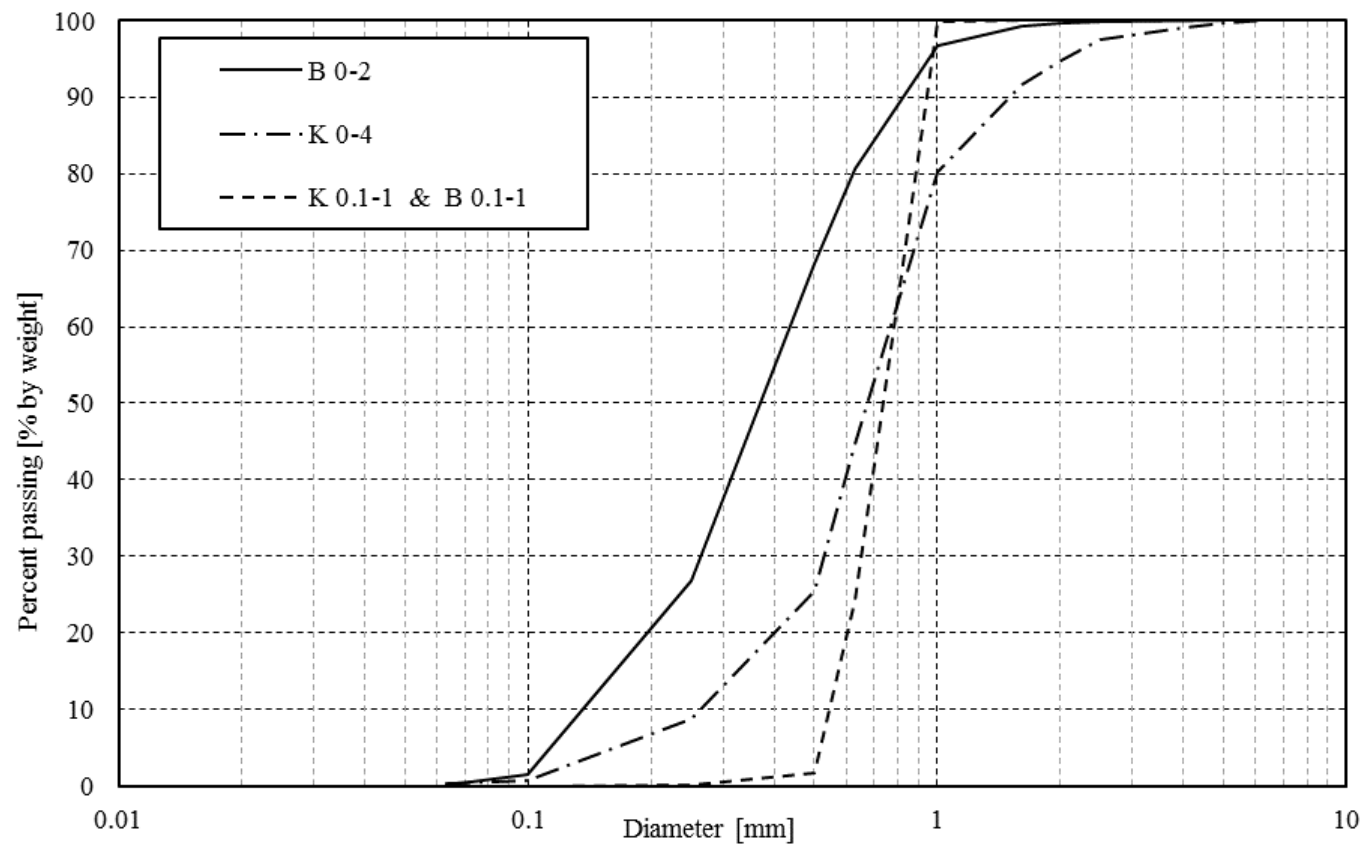

2: Grain size distribution curves of the 4 sands

II: Grain size characteristics of the 4 sands

\begin{tabular}{lccccc}
\hline \multicolumn{1}{c}{ Sand type } & $d_{10}[\mathrm{~mm}]$ & $d_{17}[\mathrm{~mm}]$ & $d_{e, \text { Zunker }}[\mathrm{mm}]$ & $d_{e, \text { Zamarin }}[\mathrm{mm}]$ & $C_{U}[-]$ \\
\hline $\mathrm{B}_{0-2}$ & 0.15 & 0.19 & 0.28 & 0.30 & 2.99 \\
$\mathrm{~K}_{0-4}$ & 0.27 & 0.37 & 0.49 & 0.50 & 2.95 \\
$\mathrm{~B}_{0.1-1}$ & 0.55 & 0.59 & 0.69 & 0.70 & 1.47 \\
$\mathrm{~K}_{0.1-1}$ & 0.55 & 0.59 & 0.69 & 0.70 & 1.47 \\
\hline
\end{tabular}




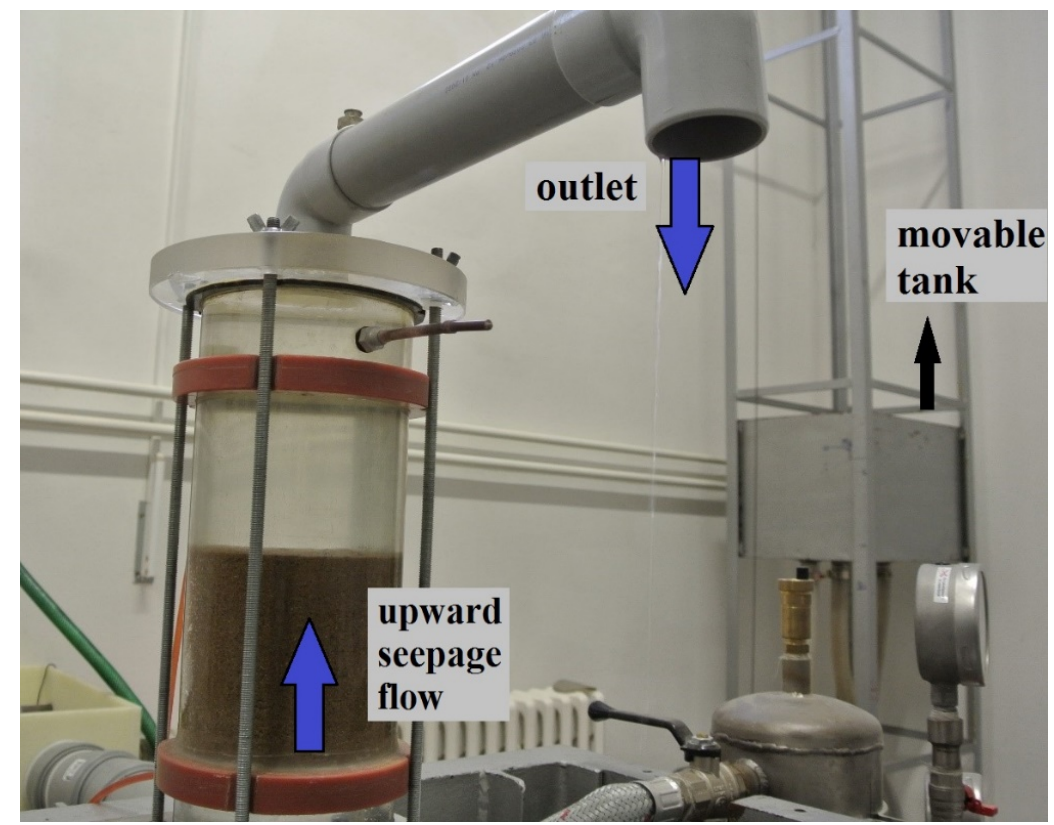

3: Photograph of the experimental apparatus

\section{RESULTS}

The dependence of the hydraulic conductivity $k$ on the porosity $n$ was evaluated separately for each type of sand (Fig. 4). The ranges of values obtained for the porosity and hydraulic conductivity are summarized in Tab. III.

Figs. 5-7 compare the measured hydraulic conductivity values with the calculated values obtained from the aforementioned empirical formulas. The ratio $k / d_{e}^{2}$ used in the plots enables the joint comparison of results for all tested samples.
The rate of agreement of each of the six empirical equations was numerically quantified using the sums of standardized squared deviations $\sum \varepsilon$ (Eq. 11). The $\sum \varepsilon$ values are summarized in Tab. IV.

$\Sigma \varepsilon=\sum_{i=1}^{M} \frac{\left(k_{\text {emp_i }}-k_{\text {mea } \_i}\right)^{2}}{k_{\text {mea } \_i} i}$,

where $k_{\text {emp }}$ and $k_{\text {mea }}$ are hydraulic conductivities obtained from empirical formulae and from measurements, respectively, and $M=40$ is the number of measurements for each sand type.

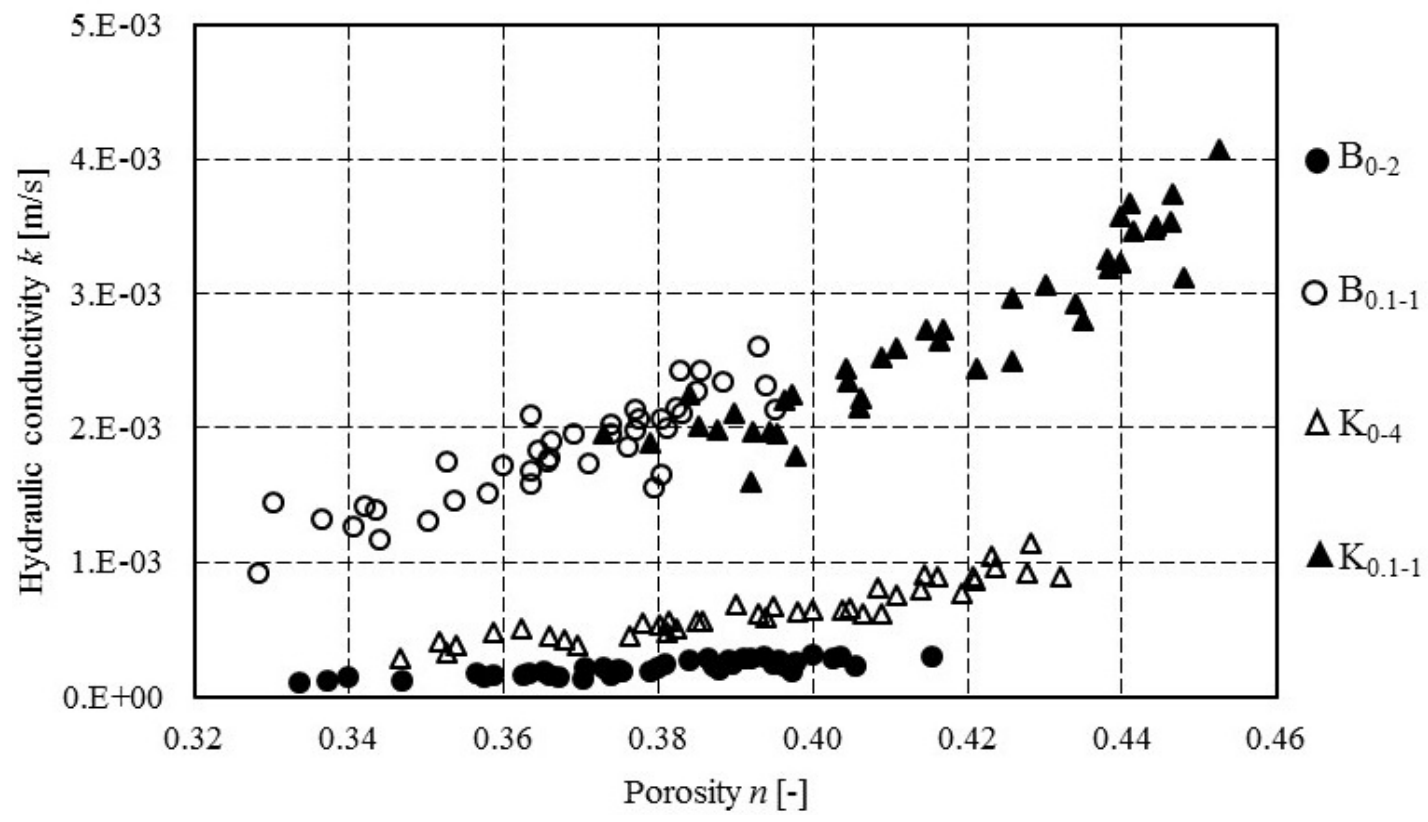

4: Dependence of hydraulic conductivity on porosity 
III: Summary of the performed experiments, with the minimum and maximum values gained for porosity and hydraulic conductivity

\begin{tabular}{lcccccc}
\hline \multirow{2}{*}{ Sand type } & \multirow{2}{*}{$\begin{array}{c}\text { Number of } \\
\text { experiments }\end{array}$} & \multicolumn{2}{c}{ Minimum } & Maximum & & \multicolumn{2}{c}{ Hydraulic conductivity [m/s] } \\
\cline { 5 - 7 } & 40 & 0.334 & 0.415 & $1.02 \times 10^{-04}$ & $3.00 \times 10^{-04}$ \\
\hline Bzenec 0/2 & 40 & 0.347 & 0.432 & $2.90 \times 10^{-04}$ & $11.5 \times 10^{-04}$ \\
Kora 0/4 & 40 & 0.328 & 0.395 & $9.26 \times 10^{-04}$ & $26.1 \times 10^{-04}$ \\
Bzenec 0.1/1 & 40 & 0.373 & 0.453 & $16.0 \times 10^{-04}$ & $40.6 \times 10^{-04}$ \\
\hline Kora 0.1/1 & 40 & &
\end{tabular}

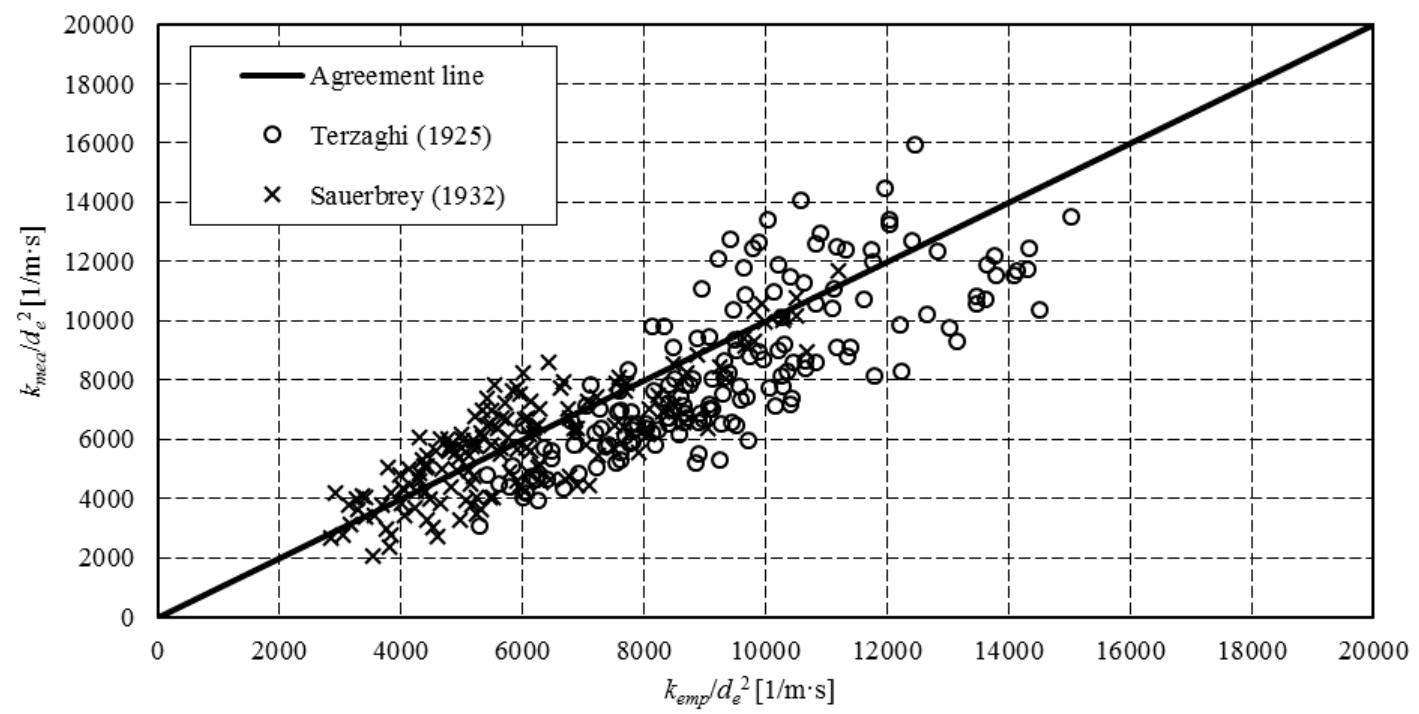

5: Comparison of calculated and measured hydraulic conductivities - part 1

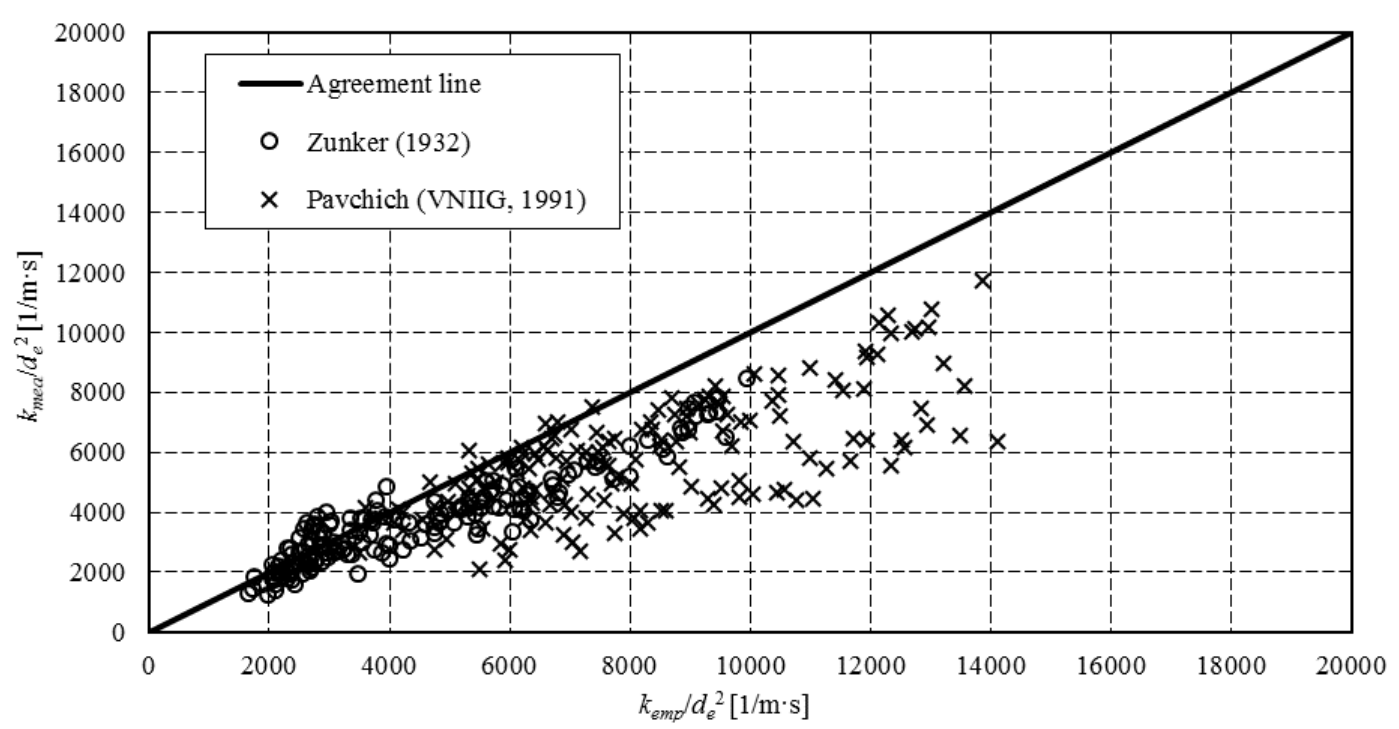

6: Comparison of calculated and measured hydraulic conductivities - part 2 


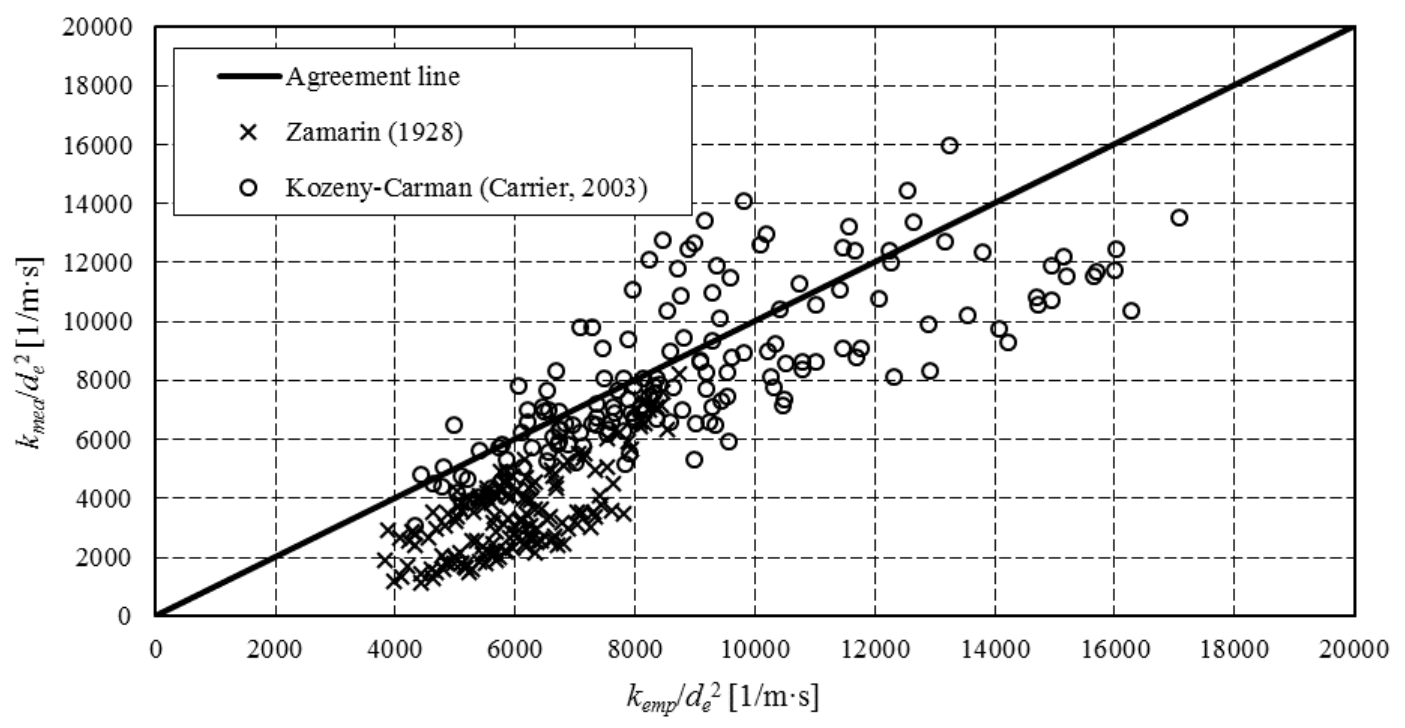

7: Comparison of calculated and measured hydraulic conductivities - part 3

IV: Sums of standardized squared deviations for empirical formulae (ascending order)

\begin{tabular}{lcc}
\hline \multicolumn{1}{c}{ Author } & Eq. number & $\Sigma \varepsilon$ \\
\hline Terzaghi (1925) & $(1)$ & 12.03 \\
Sauerbrey (1932) & $(2)$ & 8.32 \\
Zunker (1932) & $(6)$ & 14.37 \\
Zamarin (1928) & $(7)$ & 206.91 \\
Pavchich (VNIIG, 1991) & $(9)$ & 65.78 \\
Kozeny-Carman (Carrier, 2003) & $(10)$ & 19.30 \\
\hline
\end{tabular}

\section{DISCUSSION}

In Figs. 5-7 it can be seen that there are no fundamental differences between the empirical formulae listed above; the tendency of the results for each formula is to approximately match the agreement line. This can be attributed to the fact that the materials used in the experiments fulfilled the conditions for the use of the empirical formulae. Also, materials from the Kora quarry provide higher porosity (Fig. 4). This was given by more angular grain shape than in case of Bzenec sand. Obtained higher porosities then lead to higher hydraulic conductivities.

Analysis of the tendency of the results displayed in Figs. 5-7 shows that the best fit with the measured hydraulic conductivities is provided by the formulae published by Terzaghi (1925) and Sauerbrey (1932). In addition to those, the formulae proposed by Zunker (1932), Pavchich (VNIIG, 1991)
V: Minimum and maximum values for the agreement ratio $\mathrm{A}$

\begin{tabular}{lll}
\hline \multicolumn{1}{c}{ Author } & $\mathrm{A}_{\min }$ & $\mathrm{A}_{\max }$ \\
\hline Terzaghi (1925) & 0.74 & 1.73 \\
Sauerbrey (1932) & 0.70 & 1.71 \\
Zunker (1932) & 0.72 & 1.81 \\
Zamarin (1928) & 1.06 & 3.86 \\
Pavchich (VNIIG 1991) & 0.86 & 2.66 \\
Kozeny-Carman (Carrier 2003) & 0.66 & 1.69 \\
\hline
\end{tabular}

and Kozeny-Carman (Carrier 2003) provide a reasonable degree of agreement. The worst agreement is provided by the formula published by Zamarin (1928). The rate of agreement can be simply understood by computing the ratios between the calculated and experimentally measured hydraulic conductivity values and defining the minimum and maximum values for those agreement ratios, as follows:

$A=\frac{k_{\text {emp }}}{k_{\text {mea }}}, A_{\text {min }}=\min (A), A_{\text {max }}=\max (A)$,

where $A$ is the agreement ratio (best fit corresponds to $A=1$ ).

Therefore, the agreement ratio $A$ was computed for all measurements with all formulae. The minimum $A_{\min }$ and maximum $A_{\max }$ values for the agreement ratio $A$ were defined for each formula, summarized in Tab. V and plotted in Fig. 8. 


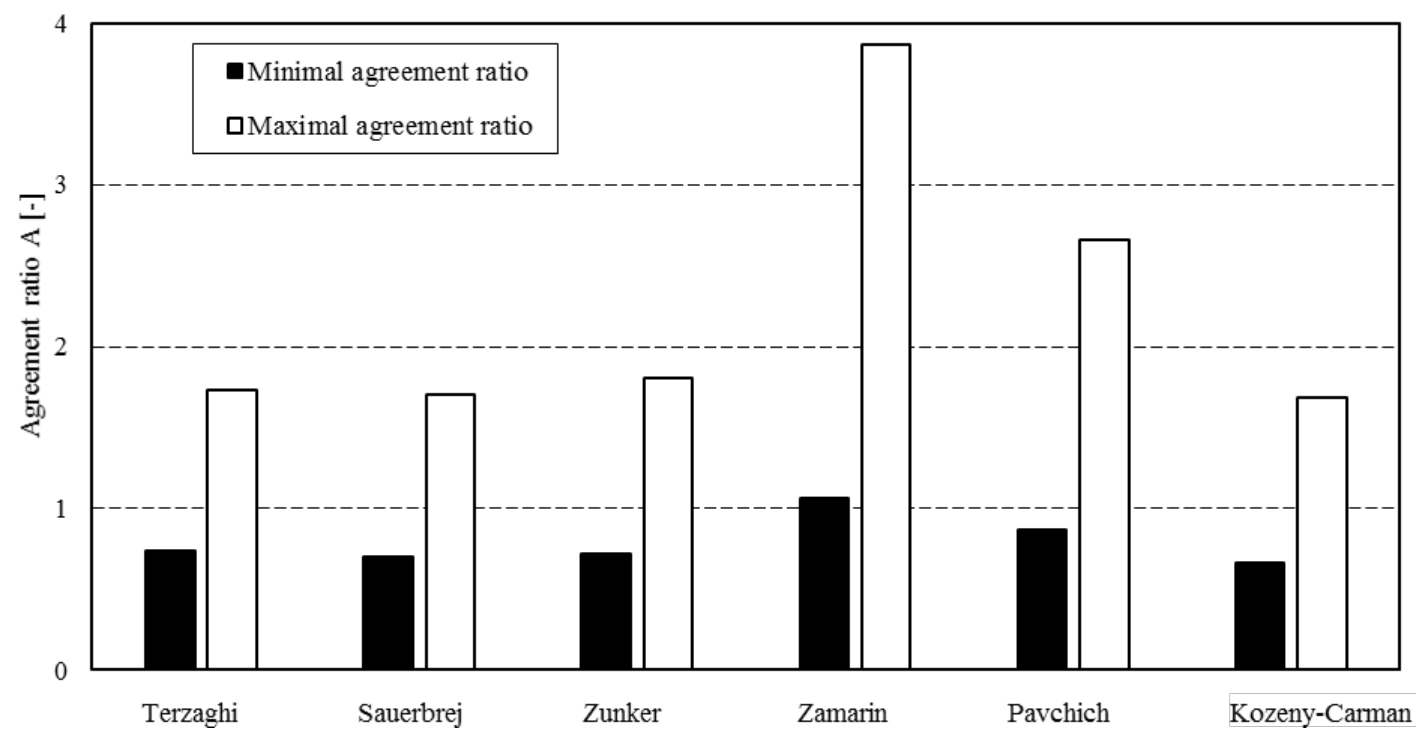

8: Minimum and maximum values for the agreement ratio $A$

\section{CONCLUSION}

In this paper, six selected empirical formulae for the determination of hydraulic conductivity were presented and the conditions for their use were mentioned. In total, 160 laboratory experiments were performed in order to evaluate the applicability of the selected empirical formulae for four different types of sand.

Comparison of the measured hydraulic conductivity values with the calculated values obtained from the empirical formulae was performed. The rate of agreement of each empirical formula with the measurements was numerically quantified using the sums of standardised squared deviations $\sum \varepsilon$ as summarized in Tab. IV.

The best fit was provided by the formulae published by Terzaghi (1925) and Sauerbrey (1932) (Fig. 5). A reasonable degree of agreement was provided by the formulae published by Zunker (1932), Pavchich (VNIIG, 1991) and Kozeny-Carman (Carrier, 2003) (Figs. 6, 7). Those empirical formulae either overestimated or underestimated the hydraulic conductivity in comparison to the conducted measurements, while the formula published by Zamarin (1928) completely underestimated the measured hydraulic conductivity (Fig. 7) and provided the worst agreement.

During sample preparation, samples with more spherical grains showed a greater tendency towards compaction and thus exhibited lower porosity and hydraulic conductivity, as mentioned before. This demonstrates the direct influence of grain shape on hydraulic conductivity. Due to this fact, the factor of grain shape should be taken into consideration when evaluating the applicability of empirical formulae. Further research may focus on the possibility of inserting the factor of grain shape into the conditions of use of each proposed empirical formula.

\section{Acknowledgements}

This study was supported by the following projects: FAST-J-18-5328: The Problematics of external suffosion /heave (boiling) and FAST-J-20-6315 Determination of the uncertainties at selected hydraulic problems.

\section{REFERENCES}

CARRIER, W. D. 2003. Goodbye Hazen; Hello, Kozeny-Carman. Journal of Geotechnical and Geoenvironmental Engineering, 129(11): 1054-1056.

GHAFOORI, Y., MAČEK, M., VIDMAR, A., ŘÍHA, J. and KRYŽANOWSKI, A. 2020. Analysis of Seepage in a Laboratory Scaled Model using Passive Optical Fibre Distributed Temperature Sensor. Water, 12(2): 367.

HAZEN, A. 1892. Some physical properties of sand and gravel with special reference to their use in filtration. 24 ${ }^{\text {th }}$ Annual Report. Boston: Massachusetts State Board of Health.

JULÍNEK, T., DUCHAN, D. and ŘÍHA, J. 2020. Mapping of uplift hazard due to rising groundwater level during floods. J. Flood Risk Management, special issue: e12601. 
KASENOW, M. 2002. Determination of hydraulic conductivity from grain size analysis. Highland Ranch, CO: Water Resources Publications.

KOZENY, J. 1927. About the capillary pipe of water in soil [in German: Über kapillare Leitung der Wasser in Boden]. Sitzungsber Akad. Wiss.,Wien, 136(2a): 271-306.

KOZENY, J. 1953. The water in soil, motion ground water [in German: Das Wasser in Boden, Grundwasserbewegung]. In: Hydraulik. Springer-Verlag Vienna, pp. 380-445.

KRÜGER, E. 1918. The motion of ground water [in German: Die Grundwasserbewegung]. Internat. Mitt. Bodenkunde, 8(5/6): 105-122.

PETRULA, L., ŘÍHA, J. and JULÍNEK, T. 2018. Evaluation of groundwater contamination in former military airport area. Gradevinar, 70(4): 369-375.

ŘíHA, J., PETRULA, L., HALA, M. and ALHASAN, Z. 2018. Assessment of empirical formulae for determining the hydraulic conductivity of glass beads. Journal of Hydrology and Hydromechanics, 66(3): 337-347.

SAUERBREY, I. I. 1932. On the Problem and Determination of the Permeability Coefficient [in Russian: К вопросу о коэффициенте фильтрации грунтов и методике его исследования, Известия]. In: Proceedings VNIIG. No. 3-5, pp. 115-145 and 173-206.

SLICHTER, C.S. 1899. Theoretical investigation of the motion of ground waters. U.S. Geological Survey $19^{\text {th }}$ Annual Report, Part 2. Washington, DC: United States Government Printing Office.

TERZAGHI, C. 1925. Principles of Soil Mechanics. Engineering News Record, 95(19): 832-836.

VNIIG. 1991. Recommendations on the laboratory methods of investigation of the permeability and filtration stability of soils. [in Russian: Рекомендащии по методике лабораторных испытаний грунтов на водопронииаемость и суффозионную устойчивостьс]. P 49-90/VNIIG. Leningrad: VNIIG.

VUKOVIĆ, M. and SORO, A. 1992. Determination of hydraulic conductivity of porous media from grain - size composition. Littleton, CO: Water Resources Publications.

ZAMARIN, E. A. 1928. The calculus of the groundwater flow [in Russian: Расчет движения грунтовых вод]. Izd-vo. Tashkent: IVCH.

ZUNKER, F. 1932. Fertilization and soil science [in German: Düngung und Bodenkunde], Zeitschrift für Pflanzenernährung und Bodenkunde, A25, pages.

\section{LIST OF SYMBOLS}

A ........ agreement ratio

$A_{\max } \ldots$ maximum value of the agreement ratio ...............................................................................................

$A_{\min } \ldots . .$. minimum value of the agreement ratio .................................................................................................. $[-]$

$C_{K C}^{m} \cdots . . . e$ empirical coefficient proposed by Kozeny-Carman (Carrier, 2003) ....................................................... [-]

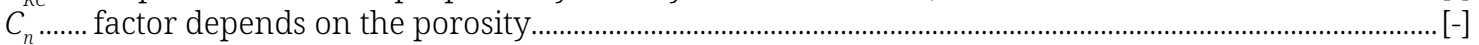

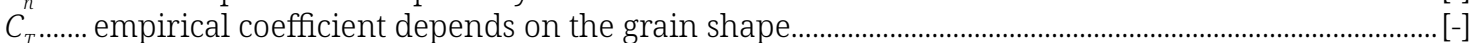

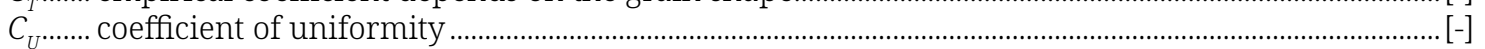

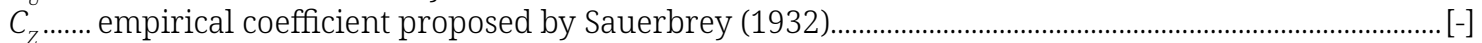

$C_{Z A} \ldots . .$. empirical coefficient proposed by Zamarin (1928) ............................................................................... [-]

$C_{Z U} \ldots .$. empirical coefficient depends on the porous medium ................................................................. [-]

$d_{1} \ldots \ldots . . .$. largest diameter of the finest fraction .............................................................................................. [m]

$d_{10} \ldots .$. grain diameter for $10 \%$ finer by weight.............................................................................................. [m]

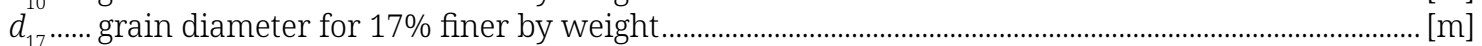

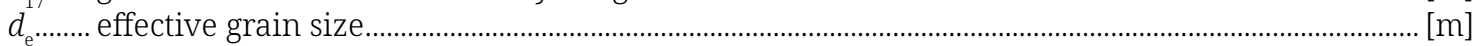

$d_{i}^{d} \ldots \ldots . .$. minimum grain diameter corresponding to the $i$-th fraction ....................................................... [m]

$d_{i}^{g}$....... maximum grain diameter corresponding to the $i$-th fraction ........................................................ [m]

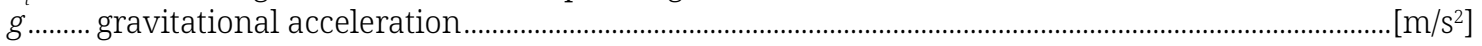

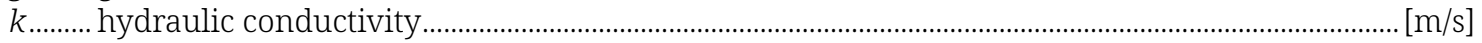

$k_{\text {emp }}$.... hydraulic conductivity obtained from empirical formulae............................................................... [m/s]

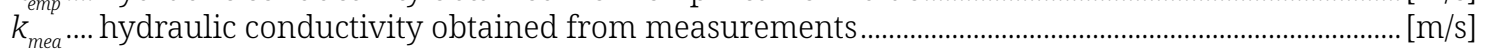

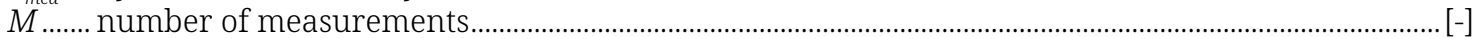

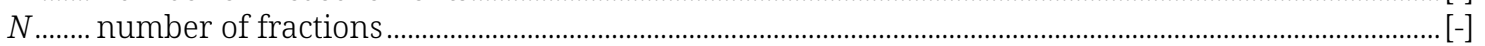

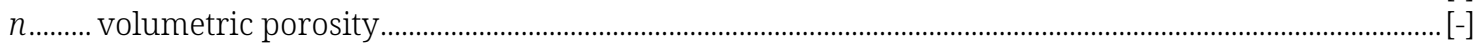

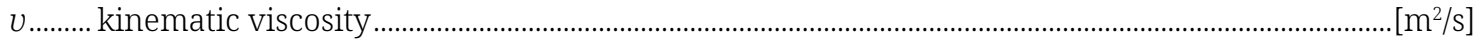

$\Delta g_{1} \ldots .$. weight of the finest fraction .................................................................................................. [kg]

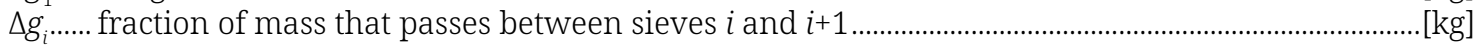

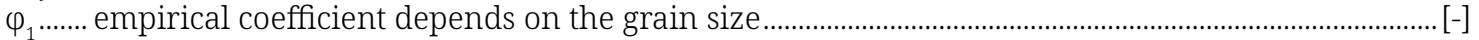

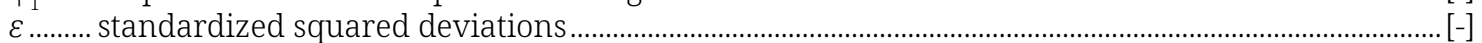


Mario Hala: hala.m@fce.vutbr.cz

Contact information

Zakaraya Alhasan: alhasan.z@fce.vutbr.cz

(c) (i) $(-)$ This work is licensed under a Creative Commons Attribution-NonCommercial-NoDerivatives 4.0 c. ${ }_{\mathrm{BY}}$ NC ND (CC BY-NC-ND 4.0) International License 